\title{
Análise do Índice de Vegetação por Diferença Normalizada do córrego Lombo em Maringá, Paraná
}

\author{
Analysis of the Normalized Difference Vegetation Index of the stream Lombo in \\ Maringa, Paraná
}

Análisis del Índice de Vegetación de Diferencia Normalizada del río pequeño Lombo en Maringá, Paraná

\author{
Renan Valério Eduvirgem \\ Doutorando em Geografia, UEM, Brasil \\ georenanvalerio@gmail.com \\ André Jesus Periçato \\ Mestrando em Geografia, UEM, Brasil \\ andrejesus_91@hotmail.com \\ Claudemir Rodrigues Soares \\ Mestrando em Geografia, UEM, Brasil \\ rodrisoaresmi@gmail.com
}




\section{RESUMO}

O presente artigo tem como objetivo promover a análise do Índice de Vegetação por Diferença Normalizada (NDVI) para acompanhamento da evolução da vegetação no fundo de vale da Bacia Hidrográfica (BH) do Córrego Lombo, com a finalidade de identificar se houve o respeito quanto à sua preservação e densidade. Para a obtenção do NDVI foram obtidas imagens dos satélites Landsat 5 (Multispectral Scanner) e Landsat 8 (OLI) na Órbita 222 no Ponto 76, disponíveis em United States Geological Survey (USGS). Para a análise cronológica das imagens, elencamos o mês de fevereiro para os anos de 1989, 1991, 1992, 2017 e 2018, pois dessa forma manteve-se o padrão da mesma estação do ano, assim, assemelhando as condições climáticas e as práticas de utilização do solo, pois como se trata de uma área agrícola a variação dos meses influencia no índice de vegetação. Para o mapa de declividade utilizou-se as classes de declividade conforme a metodologia de ROSS (1994) que o autor estabeleceu os seguintes intervalos de classes: $<3 \%, 3$ a $6 \%, 6$ a $12 \%, 12$ a $20 \%, 20$ a $30 \%, 30$ a 50\% e $>50 \%$. Concluímos que a BH apresentou um período em que não se havia preservação da APP na zona rural, no final da década de 1980 e início de 1990. Entretanto, com a Lei Federal 12.651/2012 a situação tornou-se contrária, havendo a preservação da vegetação ao longo da rede de drenagem da área em estudo, além da existência dos fragmentos florestais apresentados nos anos de 2017 e 2018.

PALAVRAS-CHAVE: Área de Preservação Permanente. Satélite. Degradação.

\section{ABSTRACT}

The objective of this article is to promote the analysis of the Normalized Difference Vegetation Index (NDVI) for monitoring the evolution of vegetation at the bottom of the valley of the River Basin (BH) of the Stream Lombo, with the purpose of identifying if there is respect for their preservation and density. For the obtaining of the NDVI were obtained images of Landsat 5 satellites (Landsat Multispectral Scanner) and 8 (OLI) in orbit 222 in Section 76, available in United States Geological Survey (USGS). For the chronological analysis of images, we list the month of February for the years 1989, 1991, 1992, 2017 and 2018, because this way remained the standard of the same season of the year, thus, resembling the climatic conditions and the practices of land use, as it is an agricultural area the variation of months influences in the vegetation index. For the map of slope we used the slope classes according to the methodology of Ross (1994) that the author has established the following ranges of classes: $<3 \%, 3$ to $6 \%, 6$ to $12 \%, 12$ to $20 \%, 20$ to $30 \%, 30$ to $50 \%$ and $>50 \%$. We conclude that the $\mathrm{BH}$ presented a period in which had not preservation of APP in the rural area, at the end of the decade of 1980 and beginning of 1990 . However, with the Federal Law 12.651/2012 the situation became contrary, with the preservation of the vegetation along the drainage network of the area under study, in addition to the existence of forest fragments presented in the years 2017 and 2018.

KEYWORDS: Permanent Preservation Area. Satellite. Degradation.

\section{RESUMEN}

El objetivo de este artículo es promover el análisis del Índice de Vegetación de Diferencia Normalizada (NDVI) para el seguimiento de la evolución de la vegetación en el fondo del valle de la Cuenca (BH) del río pequeño Lombo, con el propósito de identificar si hay respeto para su preservación y densidad. Para la obtención del NDVI se obtuvieron imágenes de los satélites Landsat 5 (escáner multiespectral Landsat) y 8 (OLI) en órbita 222 en la Sección 76, disponible en el Servicio Geológico de los Estados Unidos (USGS). Para el análisis cronológico de imágenes, ponemos en una lista el mes de febrero para los años 1989, 1991, 1992, 2017 y 2018, ya que de esta manera sigue siendo el estándar de la misma época del año, por lo tanto, asemejándose a las condiciones climáticas y las prácticas de uso de la tierra, ya que es una zona agrícola la variación de meses influye en el índice de vegetación. Para el mapa de pendiente hemos utilizado la pendiente clases según la metodología de Ross (1994), que el autor ha establecido los siguientes rangos de clases: $<3 \%$, del 3 al $6 \%, 6 \%$ y $12 \%$, de 12 a $20 \%$, del $20 \%$ al $30 \%$, de 30 a $50 \%$ y $>50 \%$. Concluimos que la $\mathrm{BH}$ presentó un período en el que no había la preservación de APP en el área rural, a finales de la década de 1980 y comienzos de 1990. Sin embargo, con la Ley Federal 12.651/2012 se convirtió en la situación contraria, con la preservación de la vegetación a lo largo de la red de drenaje de la zona en estudio, además de la existencia de los fragmentos de bosques presentados en los años 2017 y 2018.

PALABRAS CLAVE: Área de Preservación Permanente. Satélite. Degradación. 


\title{
Periódica Eletrônica
}

\section{Fórum Ambiental}

Volume 14, Número 2, 2018

ISSN 1980-0827

\author{
da Alta Paulista
}

\section{INTRODUÇÃO}

O Índice de Vegetação por Diferença Normalizada (NDVI) tem como propósito promover o acompanhamento da evolução da vegetação por meio da estimação das diferentes densidades que a vegetação pode apresentar. Este instrumento de estudo permite a organização do espaço possibilita apurar as situações de degradação que se encontra os recursos naturais e a dinâmica da vegetação do lugar (QUESADA et al., 2017). Ainda conforme o autor, há um interesse em formular estratégias para adquirir informações e monitorar os recursos da superfície:

Contudo, existe uma dificuldade no monitoramento de áreas vegetais, usualmente ligada ao difícil acesso, ao tempo e recursos necessários. Nesse sentido, o sensoriamento remoto, por meio da utilização de imagens de satélites, permite a análise de diversas áreas em diferentes períodos e, consequentemente, a análise da dinâmica da vegetação.

Ademais o sensoriamento Remoto torna-se ferramenta de suma importância para o controle e, opção para o monitoramento da cobertura do solo. Desta maneira coopera com suas ferramentas e atribuições para a utilização de índices de vegetação e analises da distribuição da vegetação no espaço. (ABREU \& COUTINHO, 2014 p. 174) salienta que na "atualidade o sensoriamento remoto vem sendo largamente aplicado para o monitoramento de coberturas vegetais, volta-se, principalmente, para seu comportamento espacial e/ou fisiológico".

Segundo (CRUZ et al., 2009) o uso e cobertura da terra é um desafio que envolve certa complexidade, devido a alta diversidade de classes e os níveis de detalhamento que pode ser alcançado, estando todos os procedimentos atrelados as técnicas de sensoriamento remoto e o processo de elaboração.

Portanto pode-se entender que as ferramentas do sensoriamento por si só não são suficientes para identificar e entender determinadas situações de degradação do solo ou da vegetação da área em estudo apenas com a adoção do sensoriamento remoto. Contudo precisa-se que o pesquisador além dos recursos estabelecidos pelo sensoriamento remoto disponíveis, não se atente somente e a essas opções como suficientes para tomar medidas adequadas sem antes realizar o trabalho de campo, pois o levantamento de campo se torna imprescindível no processo de elaboração de medidas par resolver problemas existentes no local (ABREU \& COUTINHO, 2014).

Conforme enfatiza (QUESADA et al., 2017), o Índice de Diferença de Vegetação Normalizada (NDVI), é um dos mais importantes indicadores para a análise da cobertura de vegetação em diferentes períodos utilizando técnicas de sensoriamento remoto. O objetivo deste índice é observar mudanças na cobertura do solo causadas por atividades antrópicas, assim como seu desenvolvimento. Assim, afirmamos que o NDVI é obtido por meio do processamento de imagens de satélite, com base nas diferentes refletâncias que a cobertura vegetal emite. De acordo com os autores citados pode-se entender que o NDI tem papel importante como índice para mostrar a deterioração e condição da vegetação em absorver a radiação fotossintética. 


\section{Periódica Eletrônica}

\section{Fórum Ambiental}

Volume 14, Número 2, 2018

ISSN 1980-0827

\section{da Alta Paulista}

Este índice possibilita verificar a estafe da planta numa determinada localidade da área de estudo.

Aplicações de sensoriamento remoto na pesquisa da biodiversidade frequentemente dependem do estabelecimento de relações entre a informação espectral da imagem e a diversidade de espécies de árvores medidas no campo (MADONSELA et al. 2018).

A maioria dos estudos que utilizam o índice de vegetação de diferença normalizada (NDVI) para mensurar a densidade de cobertura vegetal com base na sensibilidade da vegetação secundária ou mesmo primária que está à margem de rios e córregos, que define a variação espacial ao longo do curso d'água.

O NDVI além de mensurar as localidades com quantidades distintas de vegetação é utilizado também para investigar os impactos das diferentes condições climáticas. ZHENG et al. (2017) empregaram o NDVI em seus estudos como um indicador para refletir a resposta da dinâmica da vegetação correlacionado com o clima, para verificação de impactos climáticos. Entretanto, deve-se ter cautela com as ações antrópicas, pois as mesmas também provem a degradação ambiental. Deste modo podemos observar que diferentes pesquisadores utilizam o NDVI para diferentes finalidades, como WHETTON et al. (2017), cujos autores correlacionaram o índice de vegetação correlacionados com as propriedades do solo.

Chakraborty et al. (2018) avaliaram as mudanças negativas persistentes no verde sazonal em diferentes tipos de florestas. Fu e Burgher (2015) realizaram a análise do índice de vegetação as margens dos cursos d'água, que compõe o objetivo deste estudo, para averiguar se há ou não o respeito à legislação.

O presente artigo tem como objetivo promover a análise do Índice de Vegetação por Diferença Normalizada (NDVI) para acompanhamento da evolução da vegetação no fundo de vale da Bacia Hidrográfica $(\mathrm{BH})$ do Córrego Lombo, com a finalidade de identificar se houve o respeito quanto à sua preservação e densidade.

\section{PROCEDIMENTOS METODOLÓGICOS}

Para a obtenção do NDVI foram obtidas imagens dos satélites Landsat 5 (Multispectral Scanner) e Landsat 8 (OLI) na Órbita 222 no Ponto 76, disponíveis em United States Geological Survey (USGS). Para a análise cronológica das imagens, elencamos o mês de fevereiro para os anos de 1989, 1991, 1992, 2017 e 2018, pois dessa forma manteve-se o padrão da mesma estação do ano, assim, assemelhando as condições climáticas e as práticas de utilização do solo, pois como se trata de uma área agrícola a variação dos meses influencia no índice de vegetação. Para o ano de 1990 não localizamos imagem com condições adequadas para extração do NDVI, por este fato, este ano não foi analisado.

O realce da vegetação pelo NDVI, leva em consideração, as relações entre a refletância do sol e da vegetação, sendo que a vegetação possui elevada refletância na região do Infravermelho Próximo, já o solo na região do vermelho. Assim, quanto maior for à densidade da cobertura vegetal, inferior será a refletância na região do visível - vermelho, todavia, será superior a refletância na região do Infravermelho Próximo.

Para o cálculo de NDVI foi utilizado a seguinte equação: 
Em que:

NDVI = Índice de Vegetação por Diferença Normalizada;

$p N I R=$ reflectância na banda do infravermelho próximo;

$p R E D$ = é a reflectância na banda vermelha.

Os valores obtidos no NDVI variam entre +1 e -1 , em que, quanto mais próximo de -1 , menor a densidade da cobertura vegetal, e quanto mais próximo de +1 , maior é a densidade.

Todos os procedimentos, incluindo a confecção dos mapas, foram empregados no Software ArcGis 10.2® e o CoreIDraw X7» para finalização e organização dos mapas.

Para a construção dos mapas hipsométrico e declividade foram utilizadas uma SRTM de 30 metros, oriunda do USGS. Para o mapa hipsométrico foram elencadas 5 classes que melhor representaram a BH do Córrego Lombo. Para o mapa de declividade utilizou-se as classes de declividade conforme a metodologia de ROSS (1994) que o autor estabeleceu os seguintes intervalos de classes: $<3 \%, 3$ a 6\%, 6 a $12 \%, 12$ a $20 \%, 20$ a $30 \%, 30$ a $50 \%$ e $>50 \%$.

\section{DESCRIÇÃO E LOCALIZAÇÃO DA ÁREA}

A bacia hidrográfica do córrego Lombo está localizado no município de Maringá no Estado do Paraná. Localiza-se entre as coordenadas de $23^{\circ} 51^{\prime} \mathrm{S}$ e $52^{\circ} 00^{\prime} \mathrm{O}$ e $23^{\circ} 18^{\prime} \mathrm{S} 51^{\circ} 57^{\prime} \mathrm{O}$.

A área de estudo está situada na porção norte/ noroeste do município de Maringá, e tem sua foz junto ao Rio Pirapó. 
FIGURA 01 - Mapa de localização da Bacia Hidrográfica do Córrego Lombo, município de Maringá, Paraná

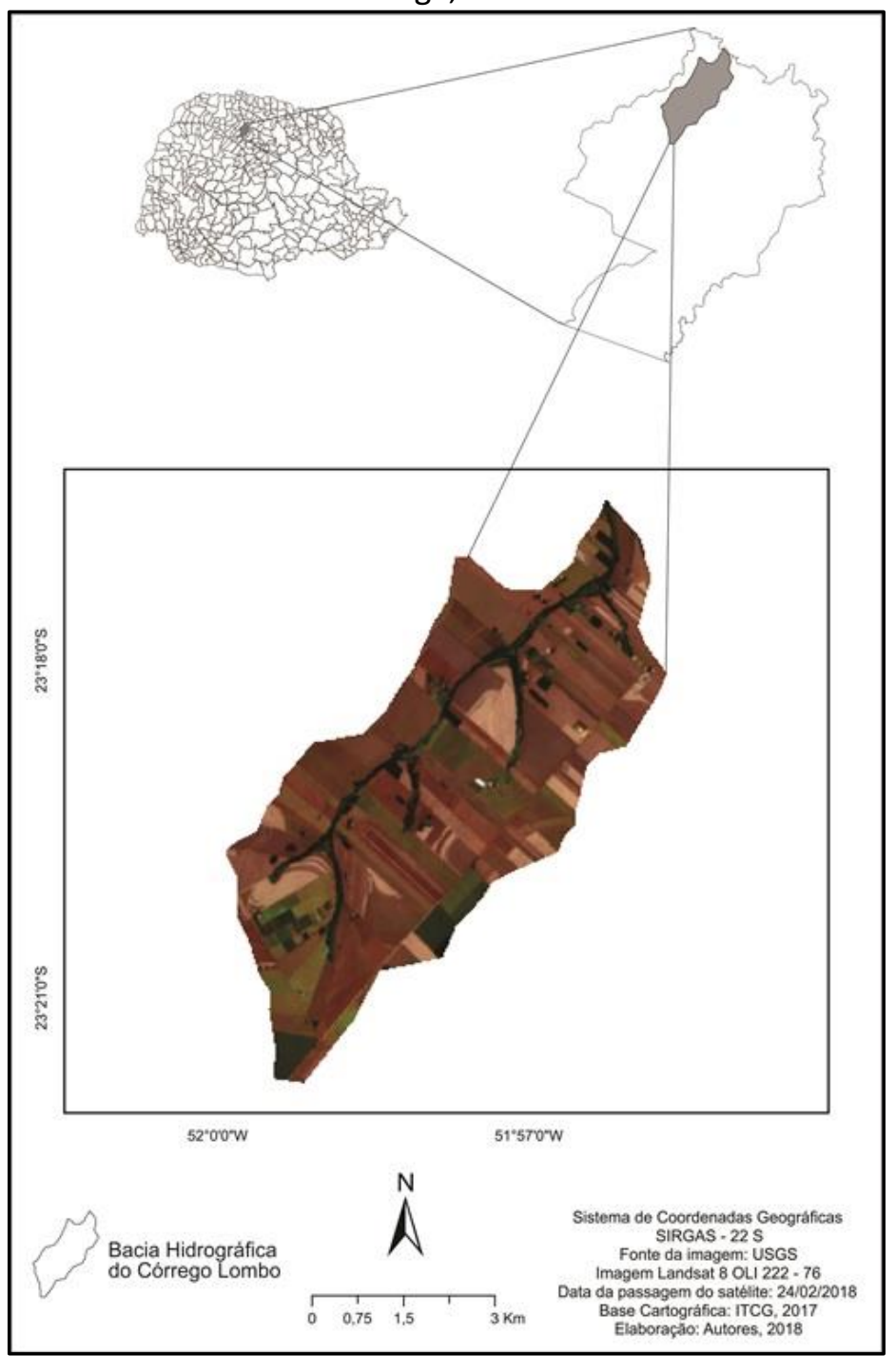

Elaboração: Autores, 2018

Quanto as características físicas da bacia hidrográfica do córrego Lombo, a mesma está localizada na porção correspondente ao Terceiro Planalto Paranaense conforme proposta apresentada por Maack (1981) que dividiu o Estado do Paraná em regiões naturais.

A geologia presente na área de estudo corresponde aos derrames básicos de lava vulcânica que se denomina como Formação Serra Geral (MINEROPAR,2001). Os derrames formaram grandes pacotes de basaltos que recobrem grande parte da região norte do Estado do Paraná. Sabe-se que a alteração das rochas por meio do intemperismo químico e físico resultam na formação de solos. A área de estudo de forma geral apresenta duas classes de solos. Os Latossolos Vermelhos textura argilosa e os Nitossolos Vermelhos textura argilosa.

Os Latossolos estão presentes nos interflúvios da bacia hidrográfica, com topos geralmente planos e com baixa declividade. Já o Nitossolo está presente na porção da média para baixa vertente, apresentando declividades médias. 


\section{Periódica Eletrônica}

\section{Fórum Ambiental}

Volume 14, Número 2, 2018

da Alta Paulista

ISSN 1980-0827

A bacia do córrego Lombo no que se refere as características quanto ao relevo, pode-se dividila em três setores (alto, médio e baixo curso). A figura 02 representa o mapa de hipsometria da bacia hidrográfica. Nota-se uma amplitude de aproximadamente 200 metros com relação ao ponto mais a montante e o ponto a jusante.

FIGURA 02 - Hipsometria da Bacia Hidrográfica do Córrego Lombo

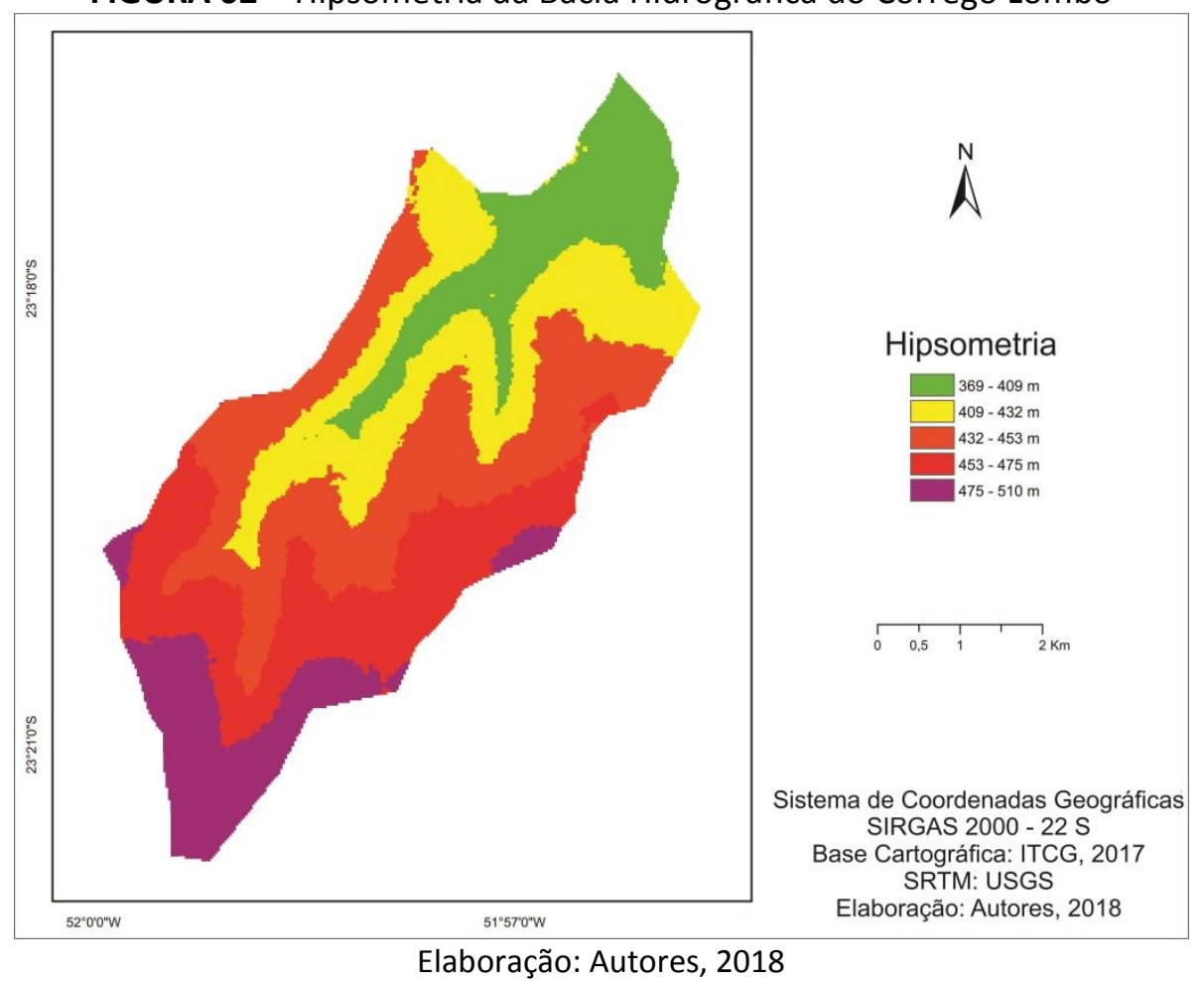

O setor do alto curso a montante apresentou valores altimétricos que variaram de 510 a 453 metros com relação ao nível do mar. Mas abaixo, no setor médio da bacia os valores foram inferiores a 453 e superiores a 409 metros. Este setor representa grande parte da área estudo, onde estão presentes os Nitossolos. Por fim, já no seu baixo curso, a bacia apresenta valores que variam de 409 a 360 metros.

A figura 03 apresenta o mapa de declividade da bacia hidrográfica do córrego Lombo. A área de estudo apresentou valores de declividade que variaram de 0 a $3 \%$ até valores aproximados a $20 \%$ de declividade. 


\section{Periódica Eletrônica}

\section{Fórum Ambiental}

Volume 14, Número 2, 2018

da Alta Paulista

ISSN 1980-0827

FIGURA 03 - Declividade da Bacia Hidrográfica do Córrego Lombo

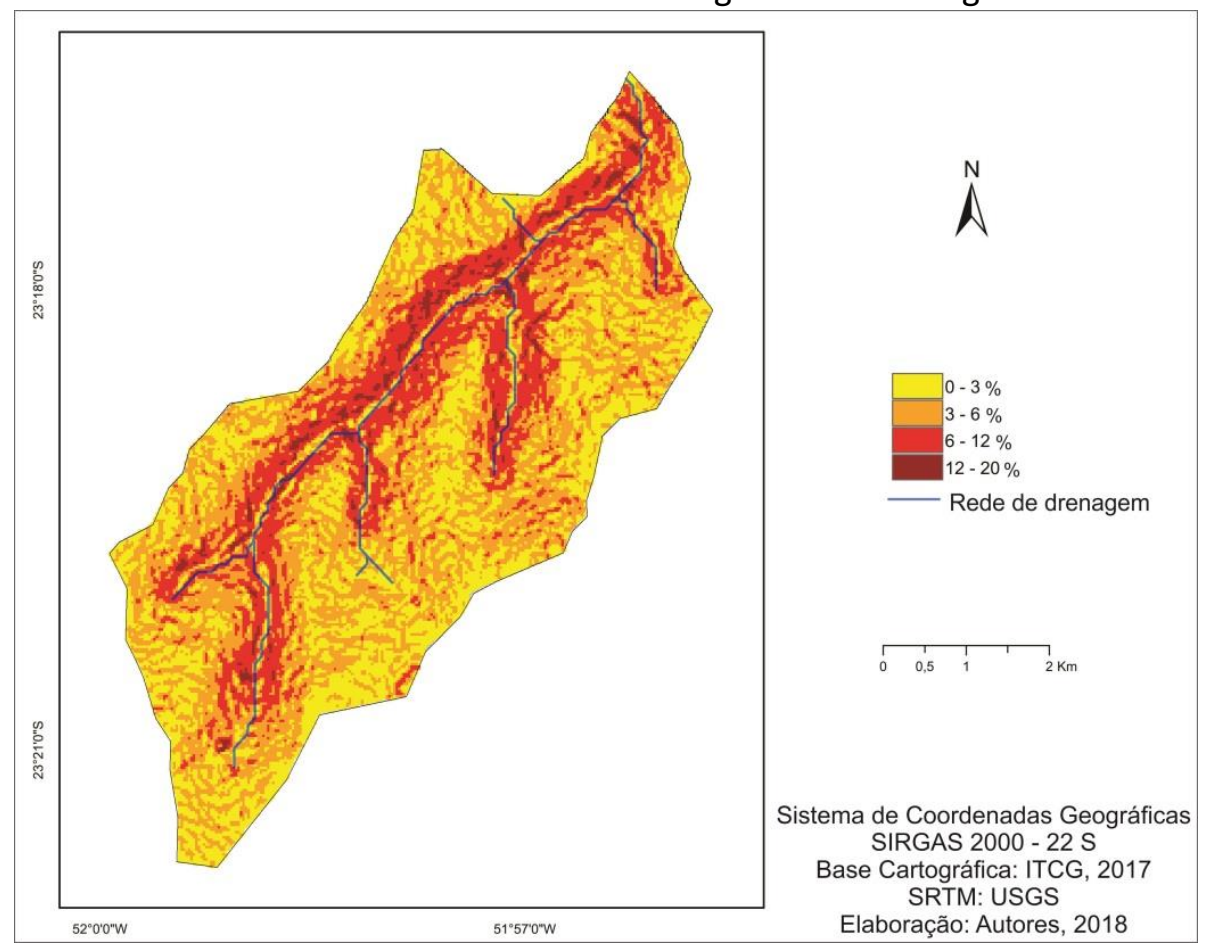

Elaboração: Autores, 2018

Os valores correspondentes a primeira e a segunda classe $(0-3 ; 3-6 \%)$ foram os mais encontrados na bacia hidrográfica, ocupando os topos aplainados e os setores médios das vertentes. As áreas com maiores declividades foram as presentes nas classes acima de $6 \%$ até $20 \%$. São áreas que estão sob influência do córrego Lombo e de seus afluentes de primeira ordem.

\section{RESULTADOS E DISCUSSÕES}

Ao promover a análise do NDVI de cada ano elencado para a cronologia apresentada foi possível perceber que ao longo do período em estudo houveram diferenças e variações quanto a diferentes densidades de vegetação na BH do Córrego lombo.

A imagem de NDVI para o ano de 1989 representou -0,33 com menor índice e 0,73 com maior índice de vegetação. Sabe-se que os valores variam de -1 a +1 a depender da condição da presença da vegetação. Na figura 04 as cores representadas pelas cores mais quentes (vermelho; alaranjado) indicam uma menor presença de vegetação, e as cores mais frias (amarelo; verde) representam as áreas com maior índice de vegetação. Desta forma fica evidente que para o ano de 1989 os valores foram bem representativos. Destaca-se para este ano o baixo índice apresentado próximo aos cursos d'água, ou seja, indicando um possível uso da terra bem próximo a rede de drenagem (Figura 04).

Já para o ano de 1991 obteve-se o maior valor quando comparado com os outros anos em análise. Para este ano o índice de vegetação mais alto foi registrado na cota de 0,77 e o menor de -0,11 predominando os elevados níveis de densidade de cobertura vegetal. Setores 
distintos da $\mathrm{BH}$ apresentaram valores maiores com os próximos a rede de drenagem. Em trechos como a montante e a jusante do córrego Lombo há valores menores de cobertura vegetal quando comparados a outros setores da bacia.

Situação semelhante ocorreu na análise do ano de 1992, onde os menores valores de índice de vegetação foram encontrados próximo ao córrego Lombo e seus afluentes. Para esses anos o uso da terra era mais diversificado com maior índice de vegetação.

A utilização do uso da terra sem respeitar as áreas próximas aos cursos hídricos podem acarretar no aumento da carga de sedimentos na rede de drenagem, sendo o curso principal desta BH o córrego Lombo.

Diante da necessidade da preservação e conscientização de seus benefícios, é instaurada a Lei Federal 12.651/2012 que no Art. $4^{\circ}$ estabelece os critérios para Área de Preservação Permanente (APP), em zonas rurais, incluindo sua metragem. No caso da área em estudo a vegetação que deve predominar é da Floresta Estacional Semidecidual, que é característica da região (IBGE, 1992).

Com a referida lei do parágrafo anterior, para os anos de 2017 e 2018 percebe-se que há uma preservação ao longo dos cursos d'água mais evidente quando comparada com os anos anteriores. Para o ano de 2017 o maior valor encontrado foi de 0,51 e para o ano de 2018 foi de 0,56 , indicando desta forma a preservação de um ano para o outro, contribuindo na diminuição da carga de sedimentos nos cursos d'água.

O uso da terra predominantemente por culturas temporárias favoreceu a análise do NDVI ao longo da rede de drenagem. Isto ocorreu pelo fato que a data da passagem do sensor foi no mês de fevereiro, período esse correspondente a colheita. 


\section{Periódica Eletrônica}

\section{Fórum Ambiental}

Volume 14, Número 2, 2018

da Alta Paulista

ISSN 1980-0827

FIGURA 04 - NDVI da Bacia Hidrográfica do Córrego Lombo
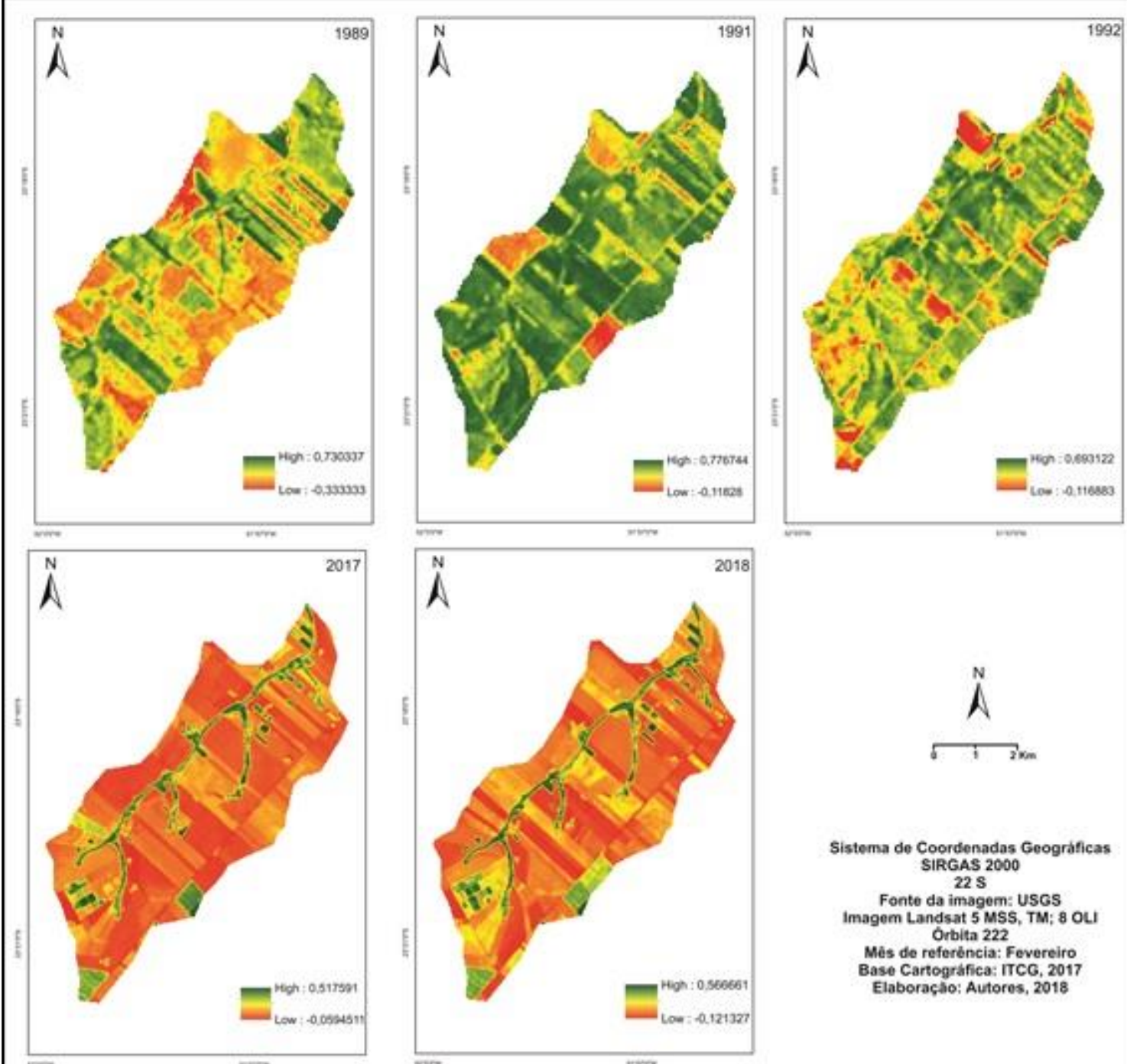

Elaboração: Autores, 2018

\section{CONCLUSÕES}

Após a realização do presente trabalho com a análise do NDVI da BH do córrego Lomba, foi possível concluir que a $\mathrm{BH}$ apresentou um período em que não se havia preservação da APP na zona rural, no final da década de 1980 e início de 1990.

Entretanto, com a Lei Federal 12.651/2012 a situação tornou-se contrária, assim havendo a, preservação da vegetação ao longo da rede de drenagem da área em estudo, além da existência dos fragmentos florestais apresentados nos anos de 2017 e 2018.

Estudos desse carácter são importantes instrumentos para gestão do território por parte do poder público. Por meio dos mesmos, torna-se possível o reconhecimento de falhas no cumprimento das leis e na preservação das bacias hidrográficas, contribuindo assim para uma melhor gestão dos recursos naturais. 


\section{REFERÊNCIAS BIBLIOGRÁFICAS}

ABREU, K. M. P.; COUTINHO, L. M. Sensoriamento Remoto aplicado ao estudo de vegetação com ênfase em índice de vegetação e métricas da paisagem. VÉRTICES, v.16, n.1, p. 173-198, jan./abr. 2014.

CHAKRABORTY, A. et al. Persistent negative changes in seasonal greenness over different forest types of India using MODIS time series NDVI data (2001-2014). Ecological Indicators, v. 85, p. 887-903, 2018.

CRUZ, C.B.M. et al. Classificação Orientada a Objetos na Geração do Mapa de Uso e Cobertura da Terra do estado do Rio de Janeiro. In: SIMPÓSIO BRASILEIRO DE SENSORIAMENTO REMOTO, Natal. Anais... p. 7789-7796, 2009.

BRASIL. Código Florestal Brasileiro. Lei 12.651, de 25 de maio de 2012. Brasília, Diário Oficial da União, 2012.

FU, B.; BURGHER, I. Riparian vegetation NDVI dynamics and its relationship with climate, surface water and groundwater. Journal of Arid Environments, v. 113, p. 59-68, 2015.

IBGE - Instituto Brasileiro de Geografia e estatística. Manual técnico da vegetação brasileira. Rio de Janeiro: IBGE, 1992.

QUESADA, Heloise Beatriz et al. Análise da vegetação ripária em bacia hidrográfica utilizando Índice de Vegetação Normalizada (NDVI) no município de Maringá-PR. Geo UERJ, n. 31, p. 439-455, 2017.

ROSS, Jurandyr Luciano Sanches. Análise empírica da fragilidade dos ambientes naturais antropizados. Revista do Departamento de Geografia, n. 8, p. 63-74, 1994.

MADONSELA, S. et al. Estimating tree species diversity in the savannah using NDVI and woody canopy cover. International Journal of Applied Earth Observation and Geoinformation, v. 66, p. 106-115, 2018.

MINEROPAR. Atlas Geológico do Estado do Paraná. 2001. Minerais do Paraná, Curitiba. 2001, 125 p. CD ROM.

WHETTON, R. et al. Nonlinear parametric modelling to study how soil properties affect crop yields and NDVI. Computers and Electronics in Agriculture, v. 138, p. 127-136, 2017.

ZHENG, Y. et al. Vegetation response to climate conditions based on NDVI simulations using stepwise cluster analysis for the Three-River Headwaters region of China. Ecological Indicators, 2017. 